\title{
A note on the current review process of Archives of Plastic Surgery
}

\author{
Seung Yong Song
}

Deputy Editor, Archives of Plastic Surgery

Department of Plastic and Reconstructive Surgery, Yonsei University College of Medicine, Seoul, Korea

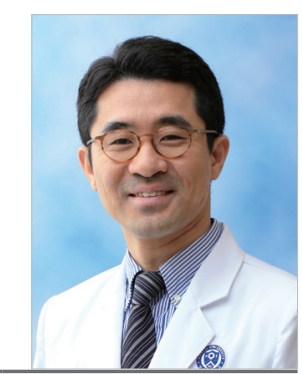

Manuscript review is a core process in journal publishing. All manuscripts submitted to Archives of Plastic Surgery (APS) undergo peer review, which refers to the critical assessment of manuscripts submitted to journals by experts who are usually not part of the editorial staff [1]. The peer review system of APS currently includes approximately 330 international reviewers, although the number of reviewers continues to increase. The reviewers of APS have always been volunteers. Sometimes, the editorial board requests someone to serve as a reviewer based on his or her academic and professional achievements. Other reviewers are approved by the editorial board in response to their voluntary application to serve as a reviewer when they submit a manuscript to APS.

Plastic surgery is a very wide-ranging field. All subspecialties, including breast surgery, eyelid surgery, nose surgery, facial rejuvenation, head and neck reconstruction, body contouring, craniofacial surgery, hand surgery, lower extremity surgery, hair surgery, and basic research, have unique operative procedures and principles. Therefore, when authors submit a manuscript, it should be evaluated by experts in the same field to ensure a fair and qualified assessment. After the review process, some manuscripts are rejected and other manuscripts are recommended to be revised. Through this process, the quality of manuscripts is improved and the reputation of the journal is enhanced. Therefore, manuscript review is a critical component of the journal publishing process, and is vital for the long-term sustainability of each journal.

Even review itself is not easy. To review a manuscript well, one needs professional knowledge and sufficient clinical experience, and moreover, it is necessary to invest considerable time and effort. Usually, experts in biomedical fields are busy due to their clinical and academic responsibilities. Nevertheless, manuscript review is usually performed without any reward. Further complicating matters, the number of experts in each field is insufficient. Therefore, many well-reputed reviewers face the burden of being requested to review manuscripts for multiple journals. Because having a fast review and decision process is an important factor in journal assessment, every journal strives to make their review process as fast as possible. This is yet another burden for reviewers. In this regard, we at APS would like to express our gratitude to all reviewers of APS, as we are aware that each reviewer sacrifices their time and energy to carry out this vitally important responsibility.

APS makes every effort to improve the quality of reviews. Principally, we assign three reviewers for original articles and have a statistician for statistical review. On our home page, we provide guidelines for review. As is well known, comments from reviewers should be specific and provide feedback that will help authors improve the quality of their manuscripts. We think that our review system contributes to the improvement of the reputation of APS.

However, reviews may be delayed when we cannot find proper experts for each manuscript, sometimes because a certain subject may be quite innovative or unique, or because reviewers cannot submit their comments until a certain time because of their own unique situations. Such circumstances are very challenging for us as editors, because journal publishing is a very complex process, in which manuscript review is the most im- 
portant step. Therefore, at APS, we continually work to expand our reviewer pool to prevent these difficult situations. Finally, we would like to express our gratitude once more to all of our reviewers, because they spend precious time and effort on the behalf of APS without compensation. We would also like to ask authors for their understanding of our complex situation regarding the review process.

\section{NOTES}

\section{Conflict of interest}

No potential conflict of interest relevant to this article was reported.

\section{ORCID}

Seung Yong Song https://orcid.org/0000-0002-3145-7463

\section{REFERENCE}

1. International Committee of Medical Journal Editors (ICMJE). Responsibilities in the submission and peer-review process [Internet]. ICMJE; c2019 [cited 2019 Jul 9]. Available from http://www.icmje.org/recommendations/browse/rolesand-responsibilities/responsibilities-in-the-submission-andpeer-peview-process.html.

Correspondence: Seung Yong Song Department of Plastic and Reconstructive Surgery, Yonsei University College of Medicine, 50-1 Yonsei-ro, Seodaemun-gu, Seoul 03722, Korea

Tel: +82-2-2228-2214, Fax: +82-2-393-6747, E-mail: iceberg554@naver.com

Received: 8 Jul 2019 • Revised: 9 Jul 2019 • Accepted: 10 Jul 2019

pISSN: 2234-6163・ elSSN: 2234-6171

https://doi.org/10.5999/aps.2019.00843 • Arch Plast Surg 2019;46:289-290 